\title{
ASPECTOS ECONÔMICOS DOS DIREITOS FUNDAMENTAIS: BENEFÍCIOS FISCAIS PARA PORTADORES DE DEFICIÊNCIA*
}

\author{
ECONOMIC ASPECTS OF THE RIGHT HUMAN \\ TAX BENEFITS FOR DISABLED PEOPLE
}

Soraya Regina Gasparetto Lunardi ${ }^{*}$

Resumo: O presente artigo trata dos direitos fundamentais e sua eficácia no caso específico das pessoas portadoras de deficiência com direito a condições especiais para compra de veículo, mas que não podem dirigir. Aponta como coerente uma interpretação sistemática integrativa e institucional do art. 111 do CTN, da Constituição Federal e das leis ordinárias, e como os Tribunais vêm decidindo tais questões. A pesquisa de campo realizada demonstra que, via de regra, as empresas não aceitam realizar a isenção de impostos quando não é o próprio portador de deficiências quem irá dirigir o veículo. Por outro lado, realizando uma interpretação sistemática verificamos decisões que efetivam tais direitos, mesmo quando o portador de deficiências não tem condições de dirigir. Por fim, a horizontalidade indireta dos direitos fundamentais, aponta a transferência da responsabilidade pela elaboração do processo de aquisição para o fornecedor e a atuação do Estado, facilitando e até premiando iniciativas nesse sentido, como forma de solução para o problema analisado.

Palavras-chave: Direitos Fundamentais, Benefícios Fiscais, Portadores de Deficiência.

Abstract: This article approaches basic rights and their efficiency in the specific case of disabled people entitled to special conditions when buying a vehicle, but who are not able to drive. It points out the coherence of a systematic integrative and legal interpretation of CTN article 111 of the Federal Constitution and ordinary laws, as well as the coherence of the Courts when solving such issues. The in loco research shows that companies do not accept to exempt customers from taxes when it is not the disabled person him/herself who will drive the car. On the other hand, when a

Este artigo é seqüência de pesquisa realizada na ITE, na área de direitos fundamentais econômicos.

Doutora em Direito Constitucional pela PUC/SP, Pós-Doutora pela Universidade de Athenas - Grécia. Coordenadora do Mestrado da UNIMAR, onde também é Professora e Pesquisadora. 
systematic analysis was conducted, we could identify decisions that favor such rights even when the disabled person is not able to drive. Finally, the straight parallel of the basic rights indicates the change of responsibility for the acquisition process to the supplier and the State action, enabling and even rewarding resolutions like those as a solution to the analyzed problem.

Keywords: Basic Rights, Tax Benefits, Disabled People.

\section{INTRODUÇÃO}

Os reflexos econômicos para a efetividade dos direitos fundamentais de pessoas portadora de deficiência física é o problema apresentado no presente estudo. Os benefícios fiscais oferecidos pela lei aos portadores de deficiência são limitados muitas vezes em razão de interpretação equivocada. É o que acontece no caso ora estudado, no qual o direito a desconto de Impostos na compra de veículo por portador de deficiência é negado pela Fazenda Nacional quando o portador de deficiência não for o condutor do veículo. Essa limitação do direito de maneira infundada, sendo inclusive a gravidade da deficiência física um fator que demonstra uma maior necessidade ao benefício e não uma razão para sua limitação. Algumas alternativas para a efetivação do direito assegurado pela lei, seus limites e reflexos, serão apresentados neste artigo.

\section{1 (IN)EFICÁCIA DOS DIREITOS FUNDAMENTAIS}

Quando falamos de direitos fundamentais não podemos deixar de pensar nas promessas constitucionais do criador de normas, e nesta receita, falta, muitas vezes, um ingrediente indispensável - a eficácia.

O problema da eficácia dos direitos fundamentais é discutido por muitos autores $^{1}$ e vem ganhando espaço. É aquilo que foi recentemente chamado “contr(a)ações dos direitos fundamentais”. Em referência à Declaração de

${ }^{1}$ José Afonso da Silva, Aplicabilidade das Normas Constitucionais, Malheiros 2003; Luís Roberto Barroso, O Direito Constitucional e a Efetividade de suas Normas, Renovar, 2003; Luiz Alberto David Araújo e Vidal Serrano Nunes Junior, Curso de Direito Constitucional, Saraiva, 2002; André Ramos Tavares, Manual de Direito Constitucional, 2005, Ingo Wolfgang Sarlet, A Eficácia dos Direitos Fundamentais, Livraria do Advogado 2004; Juan Maria Bilbao Ubillos, La eficácia de los derechos fundamentales frente a particulares - Análisis de la jurisprudencia del Tribunal Constitucional, Centro de estudios políticos constitucionales, 1997. 
Direitos da Virgínia, publicada em 1776, observou-se: "passados mais de dois séculos da redação desse texto, devemos confessar que nenhuma de suas constatações se verificou e nenhuma de suas promessas se realizou. Os homens não são livres e iguais e independentes por natureza." (DIMOULIS, 2003, p. 3). Essa contração dos direitos fundamentais vistos na perspectiva de seu real impacto é um fato que, para os não fatalistas, impõe uma ação em contrário que, no caso, será uma ação positiva, realizadora do conteúdo normativo das Constituições.

Atualmente, na Constituição, a proteção à pessoa portadora de deficiência não está condensada em um único dispositivo, mas encontra-se dispersa no texto constitucional, por exemplo, pode-se citar: art. 5ª , caput, art. 7aㅡ, XXXI, art. 37, VIII, art. 203, IV e V, art. 208, III, etc. (ARAUJO, 1997). Além das normas constitucionais, algumas leis infraconstitucionais também dispõem acerca de um tratamento diferenciado à pessoa portadora de deficiência. Este artigo tratará de algumas leis referentes ao consumo de bens e suas implicações, no intuito de analisar o problema da (falta de) eficácia a partir de um caso concreto.

As vantagens previstas em lei para essa categoria de pessoas têm seu fundamento no princípio da igualdade, que constitui o arcabouço jurídico da proteção da pessoa portadora de deficiência e proclama sua dignidade e integração social.

O patrimônio jurídico das pessoas portadoras de deficiência se resume no cumprimento do direito à igualdade, quer apenas cuidando de resguardar a obediência à isonomia de todos diante do texto legal, evitando discriminações, quer colocando as pessoas portadoras de deficiência em situação privilegiada em relação aos demais cidadãos, benefícios perfeitamente justificados e explicados pela própria dificuldade de integração natural desse grupo de pessoas. (ARAUJO, 1997).

Além disso, é preciso considerar a natureza desses direitos, bem como os constitucionalmente protegidos "direitos fundamentais", os quais tratam-se em sua maioria de princípios, que possuem como característica uma baixa densidade normativa e uma alta carga valorativa. Somado a tudo isso temos ainda a legislação infraconstitucional que também regula a matéria. Como harmonizar tais normas?

Segundo a Constituição federal de 1988, os direitos e garantias fundamentais previstos são direta e imediatamente vinculantes (efeito imediato dos direitos fundamentais). É o que determina o $\S 1^{\underline{a}}$ do art. 5 $5^{\underline{a}}$ da CF. Apesar dessa proclamação, não podemos esquecer que as normas constitucionais, em razão de sua natureza (forma de positivação, função e finalidade), reclamam a 
atuação concretizadora dos órgãos estatais, especialmente do legislador. Só após ter ocorrido a concretização, as normas adquirem sua plena eficácia. Ou segundo Ferreira Filho (1988, p. 43): "não é o art. 5ํㅗ $§ 1^{\underline{a}}$ que fará auto-aplicável o que não pode ser auto-aplicável”. ${ }^{2}$

Temos aqui uma constatação que é seguramente pessimista, mas que não deixa de corresponder a uma realidade normativa. Muitos direitos fundamentais, principalmente os direitos sociais e difusos, exigem ações positivas (e em particular alocação de recursos) do Estado e não podem ser aplicados sem atuação do legislador.

É claro que os referidos direitos não se reduzem a simples normas programáticas, mas sua aplicação imediata deve ser entendida como uma obrigação do legislador de cumprir seu dever de regulamentação, e dos Tribunais de suprir deficiências por meio do controle de constitucionalidade. (ROTHENBURG, 2005). ${ }^{3}$

Em relação aos princípios ${ }^{4}$ temos indicações de conduta que norteiam o legislador e as demais autoridades do Estado na elaboração-concretização do direito. ${ }^{5} \mathrm{O}$ problema em relação aos princípios é a sua baixa carga de concreção e alta carga valorativa ${ }^{6}$. Para sua aplicação será necessário recorrer aos métodos hermenêuticos de integração de conteúdo normativo para aplicar os princípios

${ }^{2}$ No mesmo sentido: SARLET, Ingo. A eficácia dos direitos fundamentais. 4. ed. Porto Alegre: Livraria do Advogado, 2004. p. 259-260.

${ }^{3}$ Cf. Sarlet (2004, p. 253-293).

${ }^{4} \mathrm{O}$ conceito de princípio é utilizado conforme a lição de Robert Alexy. Em caso de conflito normativo (colisão de princípios), o princípio pode ser mais ou menos observado ou concretizado, a ele se opondo a regra jurídica restrita à bipolaridade entre cumprimento e descumprimento (ALEXY, 2001, p. 78-86).

${ }^{5}$ Sobre os princípios gerais do direito cf. Modungo (2000, p. 103-106). O autor diferencia entre princípios gerais do direito e princípios fundamentais (previstos na Constituição) e traça classificações dos princípios fundamentais: de ordenamento originário, relativos a forma do Estado, princípio republicano, democrático e de ordenamento derivado (relativos à proteção das minorias, normas programáticas). Ver também Tavares (2001, p. 106-112) e Tavares (2003).

${ }^{6}$ Dimoulis define a densidade normativa da seguinte forma: "O termo densidade normativa faz pensar em normas "líquidas", maleáveis, que poderiam se adaptar a vários "recipientes" (dependendo de situações concretas, intenções subjetivas, momentos históricos, etc). Consideramos, contudo, que a metáfora da textura exprime melhor a natureza da norma jurídica que, atuando como "peneira”, autoriza (ou não) certas interpretações”. (DIMOULIS, 2006, p. 13). 
ao caso concreto, sempre respeitando o princípio da legalidade que impõe que o aplicador não saia da "moldura" esboçada pelos textos que aplica, sendo eles concretos ou abstratos. Isso se dá por meio de uma sentença integrativa com conteúdo correspondente ao direito positivo. Integrar é o que cabe nessa situação ao juiz. (LUNARDI, 2006).

A interpretação sistemática deve ser estabelecida com base em orientações gerais, deve tratar o direito como ordenamento, como sistema de normas que possuem ou devem possuir mediante a atividade do intérprete um sentido unitário. A partir dessa concepção tem-se que o direito não tolera contradições, devendo ser considerado como um conjunto coerente. Assim a unidade do direito é um pressuposto no momento de sua interpretação. (TAVARES, 2002, p. 70). ${ }^{7}$ No caso dos portadores de deficiência, essa análise integrada deve se dar com uma harmonização do texto consumeirista, do texto constitucional, bem como da legislação comum aplicável em relação a pessoas com necessidades especiais. $^{8}$

\section{$1.1 \mathrm{O}$ problema concreto}

Teoricamente, a pessoa portadora de deficiência que necessita de um veículo adaptado possui alguns benefícios de cunho tributário. Contudo, só podem ser levadas em consideração para fins de concessão dos benefícios (melhor dito: das medidas que objetivam a integração social dos deficientes) as adaptações do veículo descritas na Resolução 80 do CONTRAN.

As isenções previstas em tal caso dizem respeito aos seguintes tributos:

- isenção de IOF (Imposto Sobre Operações Financeiras) nas operações de financiamento para aquisição de veículo, segundo a Lei 8.383/91, art. 72, IV';

- isenção de IPI (Imposto Sobre Produtos Industrializados) na compra de veículos de passageiros, de acordo com a Lei 10.690/03, art. 1a, IV ${ }^{10}$.

${ }^{7}$ XII Constituição Integrada.

${ }^{8}$ Ver ainda Ricardo Guastini, Lezioni di Teoria costituzionale.

${ }^{9}$ Art. 72. Ficam isentas do IOF as operações de financiamento para a aquisição de automóveis de passageiros de fabricação nacional de até 127 HP de potência bruta (SAE), quando adquiridos por: [...] IV - pessoas portadoras de deficiência física, atestada pelo Departamento de Trânsito do Estado onde residirem em caráter permanente, cujo laudo de perícia médica especifique; [...].

${ }^{10}$ Art. ${ }^{2}$. O inciso II do parágrafo único do art. 8 da Medida Provisória no 2.185-35, de 24 de agosto de 2001, passa a vigorar com a seguinte redação:

Art. $2^{\underline{a}}$. A vigência da Lei no 8.989, de 24 de fevereiro de 1995, alterada pelo art. 29 da 
Porém, para se beneficiar das referidas isenções que são consideráveis do ponto de vista econômico, a pessoa portadora de deficiência irá se deparar com um difícil processo, repleto de burocracia e obstáculos que podem inviabilizar o exercício do direito.

Para ilustrar essa afirmação, apresentamos o caso de um portador de deficiência que não possa dirigir, mas que precisa de um veículo para se deslocar. Para obtenção de tais dados foi realizada pesquisa de jurisprudência, verificando que nesses casos somente com a intervenção judicial vem sendo possível a efetivação do direito.

Para a concessão do direito, de acordo com o indicado pela Receita Federal, são indicados os seguintes documentos necessários para a emissão da autorização. São eles:

1) Requerimento (Anexo I da IN 375/03), em três vias originais, dirigido ao Delegado da Delegacia da Receita Federal (DRF) ou ao Delegado da Delegacia da Receita Federal de Administração Tributária (Derat) da jurisdição do contribuinte;

2) Declaração de Disponibilidade Financeira ou Patrimonial do portador de deficiência ou autista, apresentada diretamente ou por intermédio de representante legal, na forma do Anexo II da IN 375/03, compatível com o valor do veículo a ser adquirido;

3) Laudo de Avaliação, na forma dos Anexos VII, VIII ou IX, emitido por serviço médico oficial da União, Estados, Distrito Federal ou Municípios ou por unidade de saúde cadastrada pelo Sistema Único de Saúde (SUS);

4) Para Isenção de IOF, declaração sob as penas da lei de que nunca usufruiu do benefício;

5) Certificado de Regularidade Fiscal ou Certidão Negativa de Débitos expedida pelo Instituto Nacional de Seguridade Social - INSS ou ainda,

Lei no 9.317, de 5 de dezembro de 1996, e pelo art. 2 da Lei n. 10.182, de 12 de fevereiro de 2001, é prorrogada até 31 de dezembro de 2006, com as seguintes alterações: "Art. 1". Ficam isentos do Imposto Sobre Produtos Industrializados - IPI os automóveis de passageiros de fabricação nacional, equipados com motor de cilindrada não superior a dois mil centímetros cúbicos, de no mínimo quatro portas inclusive a de acesso ao bagageiro, movidos a combustíveis de origem renovável ou sistema reversível de combustão, quando adquiridos por:

IV - pessoas portadoras de deficiência física, visual, mental severa ou profunda, ou autistas, diretamente ou por intermédio de seu representante legal. site: www.planalto.gov 
declaração do próprio contribuinte de que é isento ou não é segurado obrigatório da Previdência Social;

6) Cópia da Carteira de Identidade do requerente e/ou do representante legal;

7) Cópia da Carteira Nacional de Habilitação do adquirente ou do condutor autorizado;

8) Certidão Negativa da Procuradoria-Geral da Fazenda Nacional - PGFN.

Mesmo com toda a documentação providenciada a Fazenda Nacional não concorda com a concessão do referido benefício com base na redação original do artigo 1르, IV, da Lei n. 8.989D 95, a qual estabelecia que estariam isentos do pagamento do IPI na aquisição de carros de passeio as "pessoas, que, em razão de serem portadoras de deficiência, não podem dirigir automóveis comuns".

De acordo com o dispositivo supra-citado, por uma interpretação literal da lei tributária, conforme prevê o artigo 111 do CTN, não se conforma a Fazenda Nacional com a concessão do benefício àqueles que não podem dirigir.

\section{O CRUZAMENTO DOS UNIVERSOS PARALELOS}

Temos aqui universos normativos paralelos a serem analisados. De um lado um direito incontestavelmente público, as normas constitucionais que proclamam e garantem direitos fundamentais dos portadores de deficiência. Complementando temos ainda toda a legislação federal que garante um tratamento favorável aos portadores de deficiência, como ocorre com as comentadas isenções tributárias.

Por outro lado, temos o dispositivo do Código Tributário Nacional que prevê a interpretação literal, o que limitaria o direito à isenção somente para os portadores de deficiência que possam dirigir e impedindo a efetividade do direito para aqueles que não possam conduzir seu veículo.

A aparente ausência de ilegalidade é a primeira - e desanimadora conclusão, a segunda conclusão é a paralelidade que se constata entre os direitos dos portadores de deficiência (seus direitos sociais garantidos pelo Estado) e os direitos dos consumidores.

O caso trata de leis que beneficiam portadores de deficiência na compra de automóveis. As leis que prevêem isenção de alguns impostos buscam dar efetividade ao direito do portador de deficiência constitucionalmente assegurado, para que os consumidores tenham acesso a bens e que leis assegurem uma melhor integração social e profissional, no caso do automóvel, facilitando a locomoção e não impondo ao portador de deficiência o ônus de dirigir com esforço desproporcional àquelas pessoas que não possuem o mesmo problema físico. 
Para refletir sobre a situação é necessário refletir sobre o choque que ocorre entre um direito privado (a compra e venda realizada por meio da concessionária-revenda) e a eficácia de direitos fundamentais previstos na Constituição e concretizados na legislação tributária.

\subsection{A Eficácia}

Uma saída para o problema de falta de eficácia das referidas normas seria a exigência de vinculação de responsabilidade da empresa revendedora para a efetivação do direito do portador de deficiência. Esta deveria ser coresponsabilizada pela implementação eficaz da referida medida que faz parte das políticas públicas em prol das pessoas portadoras de deficiência. Mas isso representaria um choque de interesses, um ponto de encontro entre um direito patrimonial e um direito fundamental.

A questão deve ser analisada sob o aspecto do direito econômico. Se o consumidor com necessidades especiais não receber os benefícios citados e, em geral, previstos em leis, provavelmente não terá condições financeiras de adquirir uma série de bens. Basta lembrar que estatisticamente os portadores de deficiência pertencem a uma categoria de pessoas de baixa renda e que ao mesmo tempo o automóvel e uma outra série de produtos necessitam adaptações que repercutem em seu custo.

O Estado abre mão dos seus impostos para tentar uma integração do indivíduo, tanto pela exigência legal, como pela vantagem econômica que consegue ao integrar socialmente um indivíduo com necessidades especiais.

Teoricamente a falta de eficácia pode se relacionar com possíveis deslocamentos de competência e responsabilidade. (ROTHENBURG, 2005). Se o Estado não tem condições de dar efetividade a normas em razão da inexistência de órgãos especializados, poderia incentivar as revendedoras para que participassem do processo de concessão do benefício.

No caso do portador de deficiência seria possível a transferência da elaboração do processo para a prestadora de serviço que tem toda uma infraestrutura que possibilitaria de forma muito mais fácil o acesso à documentação necessária, vencendo inércias burocráticas e assumindo o ônus para tanto. Por outro lado, a elaboração desse processo pelo portador de deficiência significa uma dificuldade muito maior em razão de suas dificuldades e do sistema de serviços públicos.

A idéia proposta neste trabalho então é: a transferência da responsabilidade pela elaboração do complexo processo da pessoa do deficiente para o fornecedor. É o que chama a doutrina execução indireta do serviço. Hely 
Lopes Meirelles (1992) observa que isso ocorre quando a administração pública transfere a terceiros a realização de certas atividades. Aliás, essa não é uma idéia original, um exemplo das realizações nessa área oferece a Lei 11.079 de $2004,{ }^{11}$ que regulamenta parcerias público-privadas no âmbito da administração pública.

Para deixar isso mais claro devemos nos referir ao contexto social e político no qual se busca atualmente a maior eficácia dos direitos sociais e difusos.

\subsection{Estado Social x Estado Liberal}

O modelo do Estado liberal se baseia em uma idéia patrimonial de cunho prevalentemente privatista. Constitui-se em instrumento da soberania dos indivíduos, isto é, em garantia de sua liberdade, que é garantida, a princípio, independentemente das conseqüências que seu exercício possa ter para o resto da sociedade. A desapropriação de bens particulares, por exemplo, apenas seria possível se ficasse constatado interesse público, mediante a transferência forçada do domínio privado para o domínio público (estatal), e desde que houvesse o pagamento de justa e prévia indenização em dinheiro.

Nas demais hipóteses, a propriedade é tutelada. Mesmo se isso tem como efeito a preservação de enormes desigualdades sociais, justificando essa configuração pela necessidade de respeitar os indivíduos e de evitar o despotismo e paternalismo estatal.

A implementação de direitos fundamentais surgiu com o Estado liberal que deu base teórica e jurídico-constitucional ao seu desenvolvimento. A mudança para o Estado social ocorreu em vários países desde início do século XX e com maior intensidade após o fim da segunda grande guerra. Tem como características: as garantia de direitos sociais ao lado dos individuais, prestigiando a reivindicação de igualdade material. (BERCOVICI, 2003).

A desapropriação por interesse social, que não se confunde com o interesse público, é um exemplo claro dessa mudança de enfoque (do Estado liberal para o Estado social), já que há transferência forçada do domínio particular para o domínio público, sem a necessidade de prévia e completa indenização

${ }^{11} \mathrm{Na}$ concessão patrocinada, a Administração direta transfere, mediante contrato, a prestação do serviço público para empresa particular, tal como ocorre na concessão comum, porém esta recupera seu investimento de duas maneiras, mediante a cobrança de tarifas dos usuários e por meio de uma contraprestação pecuniária da Administração. Em outras palavras, o Estado complementa a remuneração da concessionária por meio de uma contraprestação pecuniária ao parceiro privado. 
em dinheiro, como se dá, por exemplo, com os artigos 182, § 4ª , III e 184 da Constituição de 1988. O fundamento que o Estado social realiza é o interesse social, como agente ativo de promoção da justiça social. (ARAÚJO; NUNES JÚNIOR, 2002; TAVARES, 2005).

O modelo jurídico do Estado social é caracterizado pela atenuação da distinção entre o direito público e o direito privado, pela funcionalização crescente da autonomia privada à vontade dos poderes públicos e o papel positivo da norma jurídica na conformação da vida econômica e social. (MONCADA, 2000).

Outra característica do Estado social é a crescente intervenção dos poderes públicos na esfera da autonomia privada. Isto significa que o direito não atribui só à autonomia privada, ou seja, as vontades e interesses privados, a solução dos problemas que surgem na seara privada. $O$ direito intervém na vontade privada para condicionar o seu exercício visando o cumprimento, principalmente, do princípio da solidariedade social.

Essa intervenção pode se dar de diversas maneiras, entre elas, pelo condicionamento de um determinado comportamento ao particular, ou seja, colocando o particular na situação de ter de proceder de determinado modo, dando-lhe certas vantagens ou para que ele conserve as vantagens que já possui. O Estado intervencionista exerce um papel de árbitro dos interesses no campo econômico e no social. Com base neste fundamento poderíamos pensar em uma normatização para responsabilizar o fornecedor no auxílio para uma maior efetivação do direito fundamental em discussão. ${ }^{12}$

Por outro lado, essa intervenção não deve visar a eliminação da vontade privada, não deve levar ao autoritarismo, não deve ser orientada por razões puramente políticas ou qualquer outra alheia à racionalidade do mercado. A economia é caracterizada pela livre iniciativa, pela combinação de planos econômicos individuais, sendo os interesses individuais ou dos agentes econômicos muito distintos, heterogêneos. Assim, a intervenção estatal deve

${ }^{12}$ Alguns autores entendem que se o Estado agisse dessa forma estaria infringindo o princípio constitucional da livre iniciativa privada que se traduz na "possibilidade de exercer uma actividade econômica privada, nomeadamente através da liberdade de criação de empresas e da sua gestão". (SANTOS; GONÇALVES; MARQUES, 1997, p. 48). Sabemos, porém que a livre iniciativa, tal como ocorre com todos os princípios, sofre continuas limitações na busca de equilíbrio com princípios que tutelam direitos e interesses contrastantes, devendo as limitações serem recíprocas e proporcionais aos seus fins. 
ser baseada na "confiança manifestada nos respectivo acerto através do comportamento racional dos agentes econômicos exprimindo pelo mercado um cálculo econômico ponderado que sintetiza a racionalidade global própria do mercado livre”. (MONCADA, 2000, p. 30).

A mudança do modelo de Estado embasa a idéia de que a transferência da atividade estatal para o setor privado torna-a mais eficiente. A tendência é de que o Estado restrinja seu papel de executor ou prestador direto de serviços, mantendo-se, no papel de regulador, provedor ou promotor destes, tal como o preconizado pelo artigo $174 \mathrm{da} \mathrm{CF} / 88$ ("Como agente normativo e regulador da atividade econômica, o Estado exercerá, na forma da lei, as funções de fiscalização, incentivo e planejamento, sendo este determinante para o setor público e indicativo para o setor privado”). Poderíamos então pensar em deixar a "execução dos direitos sociais" não mais como responsabilidade exclusiva do Estado, mas transferindo, parcialmente, o dever de sua implementação para a esfera privada?

\section{A EFICÁCIA DOS DIREITOS FUNDAMENTAIS (EFEITOS HORIZONTAIS E VERTICAIS)}

Pretendemos tratar neste item da eficácia dos direitos fundamentais entre particulares. Essa teoria permite criar uma ponte entre os nossos universos legislativos paralelos, possibilitando, notadamente, que os particulares que exercem um papel fundamental na vida econômica sejam, ainda que indiretamente, vinculados pelos direitos fundamentais.

Isso possibilita que o consumidor portador de deficiência seja tratado pela cadeia de produção e distribuição de bens não somente como um consumidor comum, mas que sejam levadas em consideração suas necessidades concretas.

Não há dúvida de que os direitos fundamentais foram historicamente elaborados para vincular os poderes públicos, estabelecendo limites ao poder público, tanto de forma negativa, proibindo certas decisões e ações, como de forma positiva, impondo deveres de atuação e tutela como tipicamente ocorre com os direitos sociais. Nessa ótica, os direitos fundamentais não vinculavam particulares e isso vale tanto em relação aos clássicos direitos liberal-individuais, como em relação aos direitos sociais. ${ }^{13}$

${ }^{13}$ Um caso interessante é o do Canadá. Sua carta de direitos e liberdades de 1982 estabelece que está expressamente destinada a proteger às pessoas contra o poder do Estado. Juan Maria Bilbao Unillos (1997, p. 278), em nota de rodapé. 
Entretanto, a recente doutrina brasileira dedicada aos direitos fundamentais retoma ensinamentos da doutrina alemã e analisa os direitos fundamentais também em sua dimensão objetiva, considerando que, seu conteúdo vincula, na qualidade de destinatários ou sujeitos passivos, também os particulares, desde que sejam respeitadas algumas condições. ${ }^{14}$

Responde-se assim de forma geral à pergunta antes apresentada. Sim, seria possível num Estado Social a "privatização" da responsabilidade de implementação de certos direitos sociais.

Temos assim na recente doutrina brasileira uma proposta de divisão dos efeitos dos direitos fundamentais em horizontais e verticais.

a) Efeito vertical - a clássica construção de que os direitos fundamentais obrigam o poder público - Estado - que se encontra em posição de superioridade e possui o dever de respeitar os direitos dos indivíduos. A superioridade do Estado se dá, evidentemente, em razão da concentração de poder, especialmente seu poder legislativo e indica a necessidade de os direitos fundamentais tutelarem interesses das pessoas contra possíveis ameaças ou omissões do Estado.

b) Efeito horizontal - se dá pela possibilidade de os direitos fundamentais vincularem terceiros, ou seja, vincularem, em determinadas situações, os particulares. (SILVA, 2005; CANARIS, 2003; SARLET, 2004; STEIINMETZ, 2004; UBILLOS, 1997, dentre outros).

Um dos argumentos daqueles que não aceitam o chamado efeito horizontal (Drittwirkung) é a necessidade de respeito da autonomia dos indivíduos em suas relações com outros sujeitos dentro do círculo do direito privado, pois os direitos de garantia à liberdade das relações jurídico-privadas não podem ficar submetidos aos chamados direitos fundamentais. ${ }^{15}$

Dentre os que aceitam os efeitos horizontais, não há um consenso sobre o alcance e a forma desta vinculação de direitos fundamentais entre particulares (direito privado x direito fundamental - eficácia horizontal). (SARLET, 2004). Mas todos afirmam que para se conseguir a efetividade pretendida deverá levar em consideração se os particulares encontram-se em uma situação de fraqueza social diante de adversários poderosos. É o que se propõe nesse estudo.

Essa interpretação surgiu por um julgado do Tribunal Constitucional Alemão

${ }^{14}$ Assim, por exemplo, os direitos políticos ou a prestação jurisdicional relacionada a direitos fundamentais (hábeas corpus, mandado de segurança) têm como único destinatário o poder público.

${ }^{15}$ Vários autores são citados nesse sentidopor Ubillos (1997, p. 279-281). 
que adotou pela primeira vez o termo Drittwirkung, traduzido para o português como efeito ou eficácia horizontal dos direitos fundamentais (ALEXY, 1996, p. 475-493; ALEXY, 1999, p. 43-47; CANOTILHO, 2003, p. 1286-1295; CANARIS, 2004; SARMENTO, 2004, p. 301-313). A visão inicial na Alemanha era que os direitos fundamentais podem se aplicar diretamente nas relações entre particulares, desde que uma das partes concentre um poder social.

A tese de "eficácia mediata" ou efeito mediato no âmbito do efeito horizontal, foi formulada originariamente por Günter Dürig e acolhida pelo Tribunal Constitucional Federal Alemão na célebre decisão "Lüth-Urteil" (BVerfGE 7, 198), de 5 de janeiro de $1958 .{ }^{16}$ Seu conteúdo básico é de que os direitos fundamentais "iluminam" (ou "irradiam") a legislação ordinária, devendo as normas em vigor serem interpretadas de forma que possa implementar os direitos fundamentais (efeito horizontal indireto). ${ }^{17}$

A aplicação desse modelo seria possível

após um processo de transmutação, caracterizado pela aplicação, interpretação e integração das cláusulas gerais e conceitos indeterminados do direito privado à luz dos direitos fundamentais, uma recepção dos direitos fundamentais pelo direito privado. (SARLET, 2004, p. 366).

A legislação citada no nosso trabalho (CTN e normas de benefícios para portadores de deficiência) estabelece a situação de vulnerabilidade do portador de deficiência, bem como a necessidade de normas especiais para a integração dos mesmos, assim uma interpretação sistemática permitiria tanto a aplicação das leis pelos juizes, como seria um indicativo do sistema para a criação de normas de eficácia horizontal indireta a serem efetivadas pelos fornecedores.

$\mathrm{Na}$ prática essas questões acabam sendo resolvidas pelo poder judiciário, no sentido de que a peculiaridade de que o veículo seja conduzido por terceira pessoa, que não o portador de deficiência física, não constitui óbice razoável ao gozo da isenção preconizada pela Lei n. 8.989/95, e, logicamente, não foi o intuito da lei. É de elementar inferência que a aprovação do mencionado ato

${ }^{16} \mathrm{O}$ acórdao encontra-se traduzido em Martins (2005, p. 301).

${ }^{17}$ Ubillos (1997, p. 305); Leonardo Martins (2005, p. 381) - Cinqüenta anos de Jurisprudência do Tribunal Constitucional Alemão, Coletânea Original Jürgen Schwabe, organização e introdução Leonardo Martins, Fundación Konrad-Adenauer - Uruguai, Montevidéo; Daniel Sarmento (2004, p. 301-13), "Direitos Fundamentais e Relações Privadas". 
normativo visa à inclusão social dos portadores de necessidades especiais, ou seja, facilitar-lhes a aquisição de veículo para sua locomoção. ${ }^{18}$

O Ministro Francilulli Netto inclusive já decidiu sobre a matéria esclarecendo que: "A fim de sanar qualquer dúvida quanto à feição humanitária do favor fiscal, foi editada a Lei $\mathrm{n}^{\mathbf{a}}$ 10.690, de 10 de junho de 2003, que deu nova redação ao artigo 1aㅡ, IV, da Lei n. 8.989/95:

ficam isentos do Imposto Sobre Produtos Industrializados - IPI os automóveis de passageiros de fabricação nacional [...] adquiridos por pessoas portadoras de deficiência física, visual, mental severa ou profunda, ou autistas, diretamente ou por intermédio de seu representante legal. (MINAS GERAIS, 2003).

\section{CONCLUSÃO}

A legislação, além de escassa, não surte muitas vezes os efeitos esperados. Como exemplo, vimos neste artigo, que algumas normas premiais ${ }^{19}$ relativas a aquisição de veículo automotor, são essenciais para a integração social da pessoa portadora de deficiência, mas que podem se mostrar insuficientes por motivos de interpretação limitadora ou imprecisão na redação do dispositivo legal.

Reforçando a afirmação sobre a dificuldade do portador de deficiência no mercado de consumo, a advogada Cláudia Maria Lazzarini ${ }^{20}$, em entrevista concedida a Deborah Moratori, em 27/11/03, afirma estar realizando uma pesquisa para comprovar que muitos bens do mercado de consumo não estão acessíveis aos portadores de deficiência. Cita vários exemplos como a ausência de nomes de remédios em braile, altura das gôndolas do supermercado, sistema dos caixas eletrônicos com tela sensitiva e altura dos mesmos, além dos casos em que existe lei prevendo um beneficio ou uma adaptação, porém as falhas na elaboração impedem sua consecução (MORATORI, 2003).

${ }^{18}$ Nesse sentido: decisão do STJ REsp nª 523.971 - MG (2003/0008527-7).

19 [...] in sede di teoria generale del diritto, delle nuove tecniche di controllo sociale, Che caratterizzano l'azione dello stato sociale dei nostri tempi e la distinguono profondamente da quella dello stato liberale clássico: l'impiego sempre più diffuso delle tecniche di incoraggiamento in aggiunta a, o in sostituzione di, quelle tradizionali di scoraggiamento. (BOBBIO, 1984, p. 14). Tradução livre: "em sede de teoria geral do direito, as novas técnicas de controle social que caracterizam a ação do Estado liberal clássico: o emprego sempre mais difundido de técnicas de encorajamento em acréscimo a ou em substituição de técnicas tradicionais de desencorajamento.” Ou seja as normas sancionatórias são substituídas pelas premiais.

${ }^{20}$ http://intervox.nce.ufrj.br/ lazarini/autora.html 
O caso prático que ilustra o presente artigo demonstra deficiências da Lei de isenção na compra de veículo automotor adaptado. Verificam-se lacunas que podem inviabilizar o exercício do um direito, que teoricamente deveria proporcionar igualdade, dignidade e integração da pessoa portadora de deficiência.

Podemos concluir que temos uma tendência de mudança do sujeito passivo, ou destinatário das obrigações de observância e proteção, que decorrem dos direitos e garantias constitucionais, vinculando o Estado pelo efeito vertical e inclusive relações de direito privado pelo efeito horizontal indireto. Essa vinculação irá englobar o poder judiciário, que também deverá proteger os direitos de particulares contra particulares.

A solução traz como dificuldade o alcance e as conseqüências dessa intervenção do Estado em direitos privados para a efetivação de direitos fundamentais. A melhor solução seria uma previsão legal, estabelecendo limites e casos específicos de atuação. Outra possibilidade seria deixar a cargo da jurisprudência e da doutrina para a regulamentação.

\section{REFERÊNCIAS}

ALEXY Robert. On the structure of legal principles. Ratio Juris. v. 13, n. 3, p. 294-304, Sep. 2000.

. Teoria da argumentação jurídica. São Paulo: Landy, 2001.

ARAUJO, Luiz Alberto David. A proteção constitucional das pessoas portadoras de deficiência. Brasília: Coordenadoria Nacional para Integração da Pessoa Portadora de Deficiência - CORDE, 1994.

ARAUJO, Luiz Alberto David; NUNES JÚNIOR, Vidal Serrano. Curso de direito constitucional. 5. ed. São Paulo: Saraiva, 2002.

BARROSO, Luís Roberto. O Direito Constitucional e a Efetividade de suas Normas. 7. ed. atual. Rio de Janeiro: Renovar, 2003.

BERCOVICI, Gilberto, O direito de propriedade e a Constituição de 1988. Algumas considerações crítica. Cadernos de Direito, Piracicaba, v. 3, n. 5, p. 67-77, dez. 2003.

BOBBIO, Norberto. Dalla struttura alla funzione. Nuovi stud di teoria del diritto. 2. ed. Milano: Edizioni di Comunità, 1984.

CANARIS, Claus-Wilhelm. Direitos fundamentais e direito privado. Trad. Ingo Wolfgang Sarlet e Paulo Mota Pinto. Lisboa: Almedina, 2003. 
A influência dos Direitos fundamentais sobre o direito privado na Alemanha. Trad. Petre Numann. In: SARLET, Ingo Wolfgang (Org.). Constituição, Direitos Fundamentais e Direito Privado. Porto Alegre: Livraria do Advogado, 2003.

CANOTILHO, José Joaquim Gomes. Direito constitucional e teoria da constituição 6. ed. Coimbra: Livraria Almedina, 2003.

DIMOULIS, Dimitri. Moralismo, positivismo e pragmatismo na interpretação do direito constitucional. Revista dos Tribunais, São Paulo, v. 88, n. 769, p. 11-27, nov. 1999.

- Palavras introdutórias sobre as crises e as contra(a)ções dos direitos fundamentais. Cadernos de direito, Piracicaba, v. 3, n. 5, p. 3-7, dez. 2003.

- Argüição de Descumprimento de Preceito fundamental. Problemas de concretização e limitação. Revista dos Tribunais, v. 94, n. 832, p. 13-36, fev. 2006.

FERREIRA FILHO, Manoel Gonçalves. A aplicação imediata das normas definidoras de direitos e garantias fundamentais. Revista da Procuradoria Geral do Estado de São Paulo, São Paulo, n. 29, p. 35-43, jun. 1988.

GUASTINI, Ricardo. Lezioni di teoria costituzionale. Torino: Ghiappichelli Editore, 2001.

LUNARDI, Soraya R. Gasparetto. A sentença determinativa reconhecida. 2006 (no prelo).

MEIRELES, Hely Lopes. Direito Administrativo Brasileiro. São Paulo: Malheiros, 1992.

MODUNGO, Franco. Principi generali dell' ordinamento. In: MENGONI, Luigi et al. Sistema e problema. Saggi di teoria dei sistemi giuridici. Torino: Giappichelli, 2000. p. 47-107.

MONCADA, Luís S. Cabral de. Direito econômico. Coimbra: Coimbra editora, 2000 .

MORATORI, Deborah. Portador de deficiência e o mercado de consumo: pesquisa quer comprovar que alguns produtos e serviços disponíveis no mercado não são acessíveis aos portadores de necessidades especiais. Disponível em: <http://www.jfservice.com.br/consumidor/arquivo/seusdireitos/2003/11/ 27-projeto/>. Acesso em: 12 dez. 2005. 
REYES LÓPES, Maria José. Derecho de consumo. Valencia: Tirant lo Blanch, 1999.

ROTHENBURG, Walter Claudius. Inconstitucionalidade por omissão e troca de sujeito. São Paulo: Ed. Revistas dos Tribunais, 2005.

SANTOS, António Carlos; GONÇALVES, Maria Eduarda; MARQUES, Maria Manuel Leitão. Direito econômico. Coimbra: Almedina, 1997.

SARLET, Ingo Wolfgang. A eficácia dos direitos fundamentais. Porto Alegre: Livraria do Advogado, 2004.

SARMENTO, Daniel. Direitos fundamentais e relações privadas. Rio de Janeiro: Lumen Juris, 2004.

SCHWABE, Jürgen. Cinqüenta anos de jurisprudência do Tribunal Constitucional Alemão. Organização e introdução Leonardo Martins. Montevidéo: Fundación Konrad-Adenauer, 2005.

SILVA, José Afonso da. Aplicabilidade das normas constitucionais. São Paulo: Malheiros, 2003.

SILVA, Luis Virgílio Afonso da. A constitucionalização do direito. São Paulo: Malheiros, 2005.

STEIINMETZ, Wilson. A vinculação dos particulares a direitos fundamentais. São Paulo: Malheiros, 2004.

TAVARES, André Ramos. Tratado de argüição de descumprimento de preceito fundamental. São Paulo: Saraiva, 2001.

. Curso de direito constitucional. Saraiva: São Paulo, 2002.

. Elementos para uma teoria geral dos princípios na perspectiva constitucional. In: LEITE, George Salomão (Org.). Dos princípios constitucionais: considerações em torno das normas principiológicas da Constituição. São Paulo: Malheiros, 2003. p. 21-51.

. A constituição integrada. São Paulo: Saraiva, 2002.

UBILLOS, Juan Maria Bilbao. La eficacia de los derechos fundamentales frente a particulares - Análisis de la jurisprudencia del Tribunal Constitucional. Madrid: Centro de estudios políticos constitucionales, 1997. 